\title{
Intubação de via aérea difícil em paciente com Síndrome de Treacher Collins: Relato de caso
}

\author{
Intubation of a difficult airway in a patient with Treacher Collins Syndrome: Case report
}

Karoline Sampaio Castôr ${ }^{1}$ Clarisse Sereno Loiola Braide ${ }^{1}$ Plínio da Cunha Leal ${ }^{2}$ Welton Rodrigues Ferreira $^{2}$ Ed Carlos Rey Moura² Caio Marcio Barros de Oliveira ${ }^{2}$

\begin{abstract}
Resumo: Síndrome de Treacher Collins é patologia altamente complexa e rara, podendo apresentar grande variação de formas clínicas. Apresenta-se usualmente com hipoplasia malar e mandibular. Tal condição representa previsão de dificuldade para o ato anestésico de intubação, tornando importante e necessária uma minuciosa avaliação pré-operatória e cuidado intensivo no perioperatório. Por essas condições, a anestesia geral costuma ser realizada através da indução de anestésicos inalatórios, uma vez que as crianças submetidas a procedimentos cirúrgicos são não cooperativas, além de haver dificuldade de se obter acesso venoso. Assim, tem-se como objetivo relatar um caso de via aérea com expectativa de intubação difícil em paciente diagnosticado com Síndrome de Treacher Collins. Relatamos um caso cuja singularidade reside na aplicação e no manejo anestésico diferente do que se tem feito em outros centros médicos ao abordar pacientes com previsão de via aérea difícil. Ao invés de se utilizar máscara laríngea (LMA) ou a intubação com laringoscópio óptico, procedeu-se a indução inalatória, sedação sem abolir respiração espontânea, visualização das estruturas para introdução do tubo endotraqueal (Cormack 3 ), acesso venoso, intubação orotraqueal e, posteriormente, indução anestésica e bloqueio neuromuscular. Julgamos importante divulgar tal relato para mostrar alternativas quando não existe fibroscopia. A Intubação sem máscara laríngea ou fibroscópio em casos de paciente com síndrome craniofacial pode ocorrer sem intercorrências com a estratégia de não se abolir a respiração do paciente, porém com leve sedação, devido à não cooperação e dificuldade de se obter acesso venoso em pacientes pediátricos.
\end{abstract}

Palavras-chave: Avaliação de via aérea, Algoritmo de via aérea difícil da ASA, Disostose mandíbulo-facial

\begin{abstract}
Although rare, Treacher Collins Syndrome is a highly complex pathology and has its causing defective gene mapped on the distal long arm of chromosome five (5q31. 3-q33.3) and may present great variability on its different clinical forms. Also known as craniofacial dysostosis, it usually presents with malar hypoplasia, mandibular hypoplasia, malformations of the pinna, among others. Such condition represents expected difficult airway intubation, making it important and necessary to perform a thorough preoperation evaluation and intensive perioperative care. Thus, general anesthesia tends to be achieved via the induction of inhalational anesthetics in children, because of their non cooperative profile as well as difficult venous access. We aim to report a case with expected difficulty in airway intubation in patient diagnosed with Treacher Collins syndromet, related clinical approaches, diagnosis and surgical treatment of the study case, and literature review. We report a unique case because the anesthetic application and management differs to what has been done in other medical centers in expected difficult airway patients. Instead of using laryngeal mask airway (LMA) device or flexible optical intubation (FOI), inhaling induction was chosen, sedation without suspending spontaneous breathing, visualization of structures for introduction of the endotracheal tube, venous access, endotracheal intubation and subsequently anesthetic induction and neuromuscular blocking. We consider it important to share this report in order to present options, especially when certain devices are not available. The intubation without laryngeal mask airway device or flexible optical intubation in patients with craniofacial syndrome may occur without complications with a strategy which does not impede the patients respiration, and moderate sedation, due to the non co-operative behavior and difficult venous access in pediatric patients.
\end{abstract}

Keywords: airway evaluation, ASA difficult airway algorithm, mandibulofacial dysostosis

\author{
${ }^{1}$ Acadêmica de Medicina, Universidade Ceuma, São Luís, MA, Brasil \\ ${ }^{2}$ Anestesiologista, Universidade Federal do Maranhão, UFMA, São Luís, MA, Brasil
}

Autor para correspondência: Plínio da Cunha Leal. Rua Pindaré n. 02 Edifício Saquarema, Apto 604, Ponta do Farol. São Luís - MA, Brasil. CEP.: 65075-837. Email: pliniocunhaleal@hotmail.com

Rev. Investig, Bioméd. São Luís, 9(2): 218-222, 2017 


\section{Introdução}

É reconhecida a prática que todo paciente deve ter sua via aérea avaliada antes de procedimento cirúrgico para estimar aspectos sobre sua manipulação, incluindo acesso na região cervical anterior ${ }^{1}$. Anestesiologistas se deparam com um número crescente de casos de pacientes pediátricos com diferentes doenças e síndromes raras que demandam intervenções cirúrgicas diversas².

A Síndrome de Treacher Collins (STC), também conhecida como disostose mandíbulo-facial, é doença altamente complexa. Constitui-se em uma malformação congênita do primeiro e segundo arcos branquiais, herdados de maneira autossômica dominante ${ }^{3}$. Teve na abordagem de Edward Treacher Collins em 1900 a descrição dos seus componentes essenciais e apresenta incidência relatada de 1:25.000 a 1:50.000 casos por nascidos vivos ${ }^{4}$.

A síndrome tem o gene causador mapeado na porção distal do braço longo do cromossomo 5 (5q31.3-q33.3) e apresenta grande variação de formas clínicas, como: obliquidade antimongolóide das fendas palpebrais, hipoplasia malar, hipoplasia mandibular, malformações do pavilhão auricular, coloboma palpebral inferior, surdez condutiva e fissura palatina, usualmente simétricas e bilaterais. Atresia de coanas ocorre ocasionalmente ${ }^{5}$. No período pósoperatório pode ocorrer edema de faringe e laringe, podendo chegar a descompensação respiratória e morte súbita em casos relatados ${ }^{3}$.

Anestesia geral costuma ser mandatória para pacientes com a síndrome, mesmo para procedimentos dentários simples, ou pacientes não cooperativos. Um paciente com perfil obstrutivo e via aérea potencialmente difícil são desafiadores para anestesiologistas no perioperatório, especialmente durante indução anestésica e extubação ${ }^{6}$.

A indução anestésica com inalatórios é a estratégia mais utilizada devido à dificuldade de se obter acesso venoso em crianças ${ }^{7}$. Ademais, há um fator preocupante que é a variação da dificuldade de intubação de acordo com o crescimento infantil. Em estudo de caso de um paciente pediátrico submetido a sete procedimentos cirúrgicos durante quinze anos, notouse que a categoria mais prevalente de dificuldade foi a descrita como intubação efetiva após duas ou mais tentativas ou registro de intubação difícil em ficha de anestesia. Isto corroborou a hipótese da necessidade de se reavaliar a via aérea de pacientes com a STC a cada abordagem cirúrgica ${ }^{8}$.

Por ser patologia rara e suscetível a complicações no ato anestésico, o paciente com STC é objeto de análise científica. Apesar de seu mecanismo e origem genética estarem bem estabelecidos, sua fisiopatologia ainda é pouco conhecida. As repercussões do manejo inadequado no momento da anestesia e sedação, além de possíveis complicações pós-operatórias fazem dessa patologia causa de morbimortalidade relevante. Sabe-se há bastante tempo que a manutenção da via aérea, a ventilação com máscara facial e a intubação traqueal podem ser difíceis em paciente com esta síndrome ${ }^{9}$.

Esse relato visa suscitar pesquisas sobre 0 tema, além de fornecer dados importantes para o desenvolvimento científico sobre essa doença e despertar a importância da investigação diagnóstica em pacientes com síndromes raras e malformações, com indicação cirúrgica e potenciais fatores complicadores para a intubação endotraqueal. Optamos pelo relato de 
um paciente pediátrico que apresenta Síndrome de Treacher Collins, com malformação marcante nos ossos faciais.

Por tudo que aqui foi apresentado, o compartilhamento desse relato com a comunidade científica é relevante, por tornar cientes os profissionais anestesiologistas de mais uma condução de caso na intubação de paciente com síndrome craniofacial rara, corroborando assim, a importância de uma avaliação préanestésica eficiente, para o planejamento e sucesso da anestesia.

\section{Relato do caso}

O paciente C. Z. O. R., tem 9 anos, é do sexo masculino, pardo, solteiro, natural e residente em São Luís - MA. O paciente apresenta síndrome congênita rara com características de micrognatismo, hipoplasia malar e má formação de orelhas.

Em acompanhamento com a equipe de Cirurgia Plástica, optou-se por realizar reconstrução de orelha, de pavilhão auricular e otoplastia bilaterais. O procedimento foi realizado no Hospital São Domingos em São Luís -MA. Devido à condição sindrômica, havia a expectativa de intubação difícil, para a qual os anestesiologistas responsáveis, após avaliação préanestésica, adotaram estratégia específica para o caso.

À admissão no centro cirúrgico, o paciente estava eupneico, normocorado, acianótico, anictérico, sem edemas, ausculta cardiopulmonar normal, peso aproximado de $33 \mathrm{~kg}$. Encontrava-se em jejum, classificação da American Society of Anesthesiologists (ASA) de estado físico (Physical Status) 2. A classificação de Mallampati não pôde ser avaliada pela não cooperação do paciente.

$\mathrm{O}$ ato anestésico teve início com monitorização (oximetria, eletrocardioscopia e pressão arterial não invasiva), colocação de máscara conectada ao aparelho de anestesia, fluxo de oxigênio a $100 \%$ de $5 \mathrm{~L} /$ minuto e sevoflurane a $5 \%$, com que se conseguiu leve aprofundamento de consciência. Depois, aprofundou-se a anestesia inalatória mantendo a respiração espontânea, realizou-se laringoscopia, quando foi observada classificação 3 de Cormack Lehane. Assim, obteve-se acesso venoso periférico (jelco $22 \mathrm{G}$ ), efetuou-se a intubação orotraqueal com tubo 5,5 e, na sequência, administração de fentanil $(100 \mu \mathrm{g})$, propofol $(80 \mathrm{mg}) \mathrm{e}$ cisatracúrio $(5 \mathrm{mg})$. Antes do início do procedimento, cefazolina $(1 \mathrm{~g})$.

O paciente foi colocado em ventilação mecânica (VC: $230 \mathrm{ml}$, FR.: 17 irpm e PEEP: 5), fração inspirada de oxigênio $40 \%$, fluxo de gases de $1 \mathrm{~L}$ e sevoflurano $2,5 \%$. Durante todo o ato cirúrgico 0 paciente apresentou saturação de oxigênio $100 \%$ e dióxido de carbono expirado variando entre $33 \%$ e $40 \%$. Não houve intercorrências, sendo feitos ondansetrona $4 \mathrm{mg}$, dipirona $1 \mathrm{~g}$ e morfina $2 \mathrm{mg}$ antes do término da operação. $O$ procedimento teve duração de 180 minutos e a extubação foi realizada quando o paciente encontrava-se bem acordado, com VC $230 \mathrm{ml}$ e FR 15 irpm. O paciente foi encaminhado para recuperação pós-anestésica e recebeu alta para casa após 24 horas.

\section{Discussão}

A adoção de protocolos e o fiel seguimento destes pelos anestesiologistas não são suficientes per si para evitar complicações sérias 
no manejo de via aérea difícil durante a anestesia1.

O gerenciamento anestésico em
crianças com deformidades
craniofaciais durante cirurgias é
complexo e requer técnicas cirúrgicas e
anestésicas especiais. O objetivo
principal em relação à segurança do
paciente é alcançado após verificação
de doenças coexistentes.

Adicionalmente, anestesia geral é uma prática comum em crianças, e a indução inalatória é a abordagem mais comum, devido à dificuldade de acesso venoso em crianças ${ }^{7}$.

Síndrome de Treacher Collins é frequentemente associada à dificuldade de intubação endotraqueal. Por outro lado, não é verdade que intubação difícil seja encontrada em todo paciente com a síndrome. Essas informações conflitantes, acerca da via aérea difícil em STC, podem ser causadas por diferenças no estágio de desenvolvimento do indivíduo ${ }^{8}$.

Pilsbury et a/10 evidenciaram em estudo com 60 casos de intubação pediátrica difícil, que em $73 \%$ dos casos utilizou-se técnica de indução inalatória e $23 \%$, técnica intravenosa pura. A razão dessa preferência pela a primeira técnica seria por familiaridade com o procedimento, desejo de se manter a criança respirando espontaneamente, e conhecimento de que é tradicionalmente o método de escolha para crianças com via aérea difícil. Tais motivos, associados a não colaboração das crianças, em especial pacientes com STC, levaram a proceder-se a indução inalatória no presente caso e a intubação subsequente. Não se tentou realizar anestesia geral com máscara laríngea, já que a cirurgia era próxima à via aérea e poderia haver deslocamento do dispositivo pela manipulação da equipe cirúrgica.

O uso de agente bloqueador neuromuscular na via aérea pediátrica difícil permanece como uma questão controversa. Embora estudos tenham mostrado que o uso de rocurônio durante indução anestésica inalatória com sevoflurano diminua significantemente a incidência de problemas respiratórios e aumenta a taxa de condições aceitáveis para intubação, a decisão para se usar vai depender da doença de base e a previsão de facilidade com que será feita a ventilação sob máscara ${ }^{10}$. Uma vez que a via aérea já estava garantida, neste caso não existia preocupação em relação ao bloqueador neuromuscular.

Verifica-se a partir da revisão bibliográfica, que os recentes trabalhos têm corroborado a prática de intubação com fibroscopia óptica (FOI - fibreoptic intubation) como padrão-ouro em via aérea difícil tanto na população pediátrica como em adultos, nos casos em que a intubação via laringoscopia direta não é possível ou quando se prevê dificuldade de intubação ${ }^{10}$.

O presente relato nos permite vislumbrar outras possibilidades de abordagem em pacientes com síndromes craniofaciais, além daquelas preconizadas nos protocolos internacionais. Principalmente ao considerar que nem todos os serviços contam com equipamentos como o fibroscópio na prática anestésica. Em casos de hipoplasia mandibular e micrognatia, presentes na STC, a língua proporcionalmente mais larga é forçada posteriormente dificultando a visualização das pregas vocais em laringoscopia direta. Assim, a porção posterior da língua e a glote são posicionadas mais agudamente, favorecendo dispositivos como: GlideScope, laringoscópio óptico Airtraq (Prodol Meditec), videolaringoscópio DCI (Karl Storz), videolaringoscópio Truview PCD e broncoscópios de fibra óptica flexíveis, bem indicados para intubação de via aérea difícil na população pediátrica 
com malformações, nos serviços que os possuem.

A fibroscopia óptica é altamente efetiva em garantir via aérea comprometida documentada, mas deve ser acompanhada de sedação prudente, anti-sialagogo e subsequente anestesia local da via (com aerosóis ou injeção local). Manutenção de respiração espontânea e patência da via aérea são componentes essenciais desta técnica ${ }^{11}$, tendo sido a estratégia exposta neste relato coerente com o descrito.

Finalmente, o compartilhamento dessas informações, mostrando que é possível ser bem-sucedido nas manobras invasivas com tubos orotraqueais mesmo sem dispositivos de fibra óptica, pode estimular outros anestesiologistas a adaptarem suas realidades, sem deixar de atender prontamente e com qualidade 0 paciente com via aérea difícil submetido a procedimentos sob anestesia.

\section{Referências}

1. Frerk C, Mitchell VS, McNarry AF, et al. Difficult Airway Society 2015 guidelines for management of unanticipated difficult intubation in adults. $\mathrm{Br} \mathrm{J}$ Anaesth. 2015; 115(6):827-848.

2. Bajwa SJ, Bajwa SK, Singh A, et al. Anesthetic challenges and difficulties in the management of Treacher Collins syndrome. Anesth Essays Res. 2011; 5(1):111-3.

3. Goel L, Bennur SK, Jambhale S. Treacher-Collins Syndrome - A Challenge For Anesthesiologists. Indian J Anaesth. 2009; 53(4):496-500.

4. Nguyen PD, Caro MC, Smith DM et al. Long-term orthognatic surgical outcomes in Treacher Collins patients. J Plast Reconstr Aesthet Surg. 2016 Mar;69(3):402-8.

5. Andrade EC, Junior VS, Didoni AL, et al. Treacher Collins Syndrome with choanal atresia: a case report and review of disease features. Braz J Otorhinolaryngol. 2005 JanFeb;71(1):107-10.

6. Lin TC, Soo LY, Chen Tl, et al. Perioperative Airway Management in a Child with Treacher Collins Syndrome. Acta Anaesthesiol Taiwan. 2009; 47(1):44-7.

7. Sinkueakunkit A, Chowchuen B, Kantanabat $C$, et al. Outcome of anesthetic management for children with craniofacial deformities. Pediatr. Int. 2013; 55(3):360-5.

8. Inagawa G, Miwa T, Hiroki K. The Change of Difficult Intubation with Growth in a Patient with Treacher Collins Syndrome. Anesth. Analg. 2004; 99(6):1874.

9. Maclennan FM, Robertson GS. Ketamine for induction and intubation in Treacher-Collins Syndrome. Anaesthesia. 1981; 36(2):196-8.

10. Pilsbury JE, Wong E, Montgomerie J. Anaesthetic management of difficult intubation in the paediatric population when direct laringoscopy initially has failed or is not possible: an audit of current practice at a tertiary paediatric hospital. PACCJ. 2015; 3(1):1-9.

11. Belanger $\mathrm{J}$, Kossick M. Methods of Identifying and Managing the Difficult Airway in the Pediatric Population. AANA J. 2015; 83(1):35-41. 